\title{
Attitudes toward concordance and self-efficacy in decision making: a cross-sectional study on pharmacist-patient consultations
}

This article was published in the following Dove Press journal:

Patient Preference and Adherence

Yew Keong $\mathrm{Ng}^{\prime}$

Noraida Mohamed Shah'

Ly Sia Loong ${ }^{2}$

Lay Ting $\mathrm{Pee}^{3}$

Sarina Anim M Hidzir ${ }^{4}$

Wei Wen Chong'

'Faculty of Pharmacy, Universiti Kebangsaan Malaysia, Kuala Lumpur, Malaysia; '2Department of Pharmacy, Universiti Kebangsaan Malaysia Medical Centre, Kuala Lumpur, Malaysia; ${ }^{3}$ Department of Pharmacy, Hospital Kuala Lumpur, Kuala Lumpur, Malaysia; ${ }^{4}$ Department of Pharmacy, Hospital Sungai Buloh, Selangor, Malaysia
Correspondence: Wei Wen Chong Faculty of Pharmacy, Universiti Kebangsaan Malaysia, Jalan Raja Muda Abdul Aziz, 50300 Kuala Lumpur, Malaysia

Tel +60392898056

Fax +6032698327

Email weiwen@ukm.edu.my
Purpose: This study investigated patients' and pharmacists' attitudes toward concordance in a pharmacist-patient consultation and how patients' attitudes toward concordance relate to their involvement and self-efficacy in decision making associated with medication use.

Subjects and methods: A cross-sectional study was conducted among patients with chronic diseases and pharmacists from three public hospitals in Malaysia. The Revised United States Leeds Attitudes toward Concordance (RUS-LATCon) was used to measure attitudes toward concordance in both patients and pharmacists. Patients also rated their perceived level of involvement in decision making and completed the Decision Self-Efficacy scale. One-way analysis of variance (ANOVA) and independent $t$-test were used to determine significant differences between different subgroups on attitudes toward concordance, and multiple linear regression was performed to find the predictors of patients' self-efficacy in decision making.

Results: A total of 389 patients and 93 pharmacists participated in the study. Pharmacists and patients scored $\mathrm{M}=3.92(\mathrm{SD}=0.37)$ and $\mathrm{M}=3.84(\mathrm{SD}=0.46)$ on the RUS-LATCon scale, respectively. Seven items were found to be significantly different between pharmacists and patients on the subscale level. Patients who felt fully involved in decision making ( $M=3.94, \mathrm{SD}=0.462)$ scored significantly higher on attitudes toward concordance than those who felt partially involved $(\mathrm{M}=3.82, \mathrm{SD}=0.478)$ and not involved at all $(\mathrm{M}=3.68, \mathrm{SD}=0.471 ; p<0.001)$. Patients had an average score of $76.7 \%(\mathrm{SD}=14.73 \%)$ on the Decision Self-Efficacy scale. In multiple linear regression analysis, ethnicity, number of medications taken by patients, patients' perceived level of involvement, and attitudes toward concordance are significant predictors of patients' self-efficacy in decision making $(p<0.05)$.

Conclusion: Patients who felt involved in their consultations had more positive attitudes toward concordance and higher confidence in making an informed decision. Further study is recommended on interventions involving pharmacists in supporting patients' involvement in medication-related decision making.

Keywords: patient-centered care, patient involvement, adherence, LATCon, shared decision making

\section{Introduction}

Medicines are the most commonly used intervention in health care, as they play an essential role in preventing illness, managing chronic conditions, and curing diseases. ${ }^{1}$ However, adherence to long-term medications is approximately $50 \%$ among patients with chronic diseases, and the numbers may be even lower in developing countries. ${ }^{2}$ Non-adherence to medication can impact the efficacy and benefits of treatment and also increase health care expenditure and utilization. ${ }^{3}$ For example, in the USA alone, 
the wastage in medicines incurs a loss of US\$177 billion annually. ${ }^{4}$

The failure to include patients' beliefs, preferences, and expectations was found to be one of the major causes of nonadherence. ${ }^{5}$ Moreover, good patient-provider communication that promotes education and encourages patient interaction has been shown to improve medication adherence. Subsequently, patients are equipped with deeper understanding and are less uncertain regarding their treatment regime. ${ }^{6}$ Furthermore, patients sometimes wish to know detailed reasons for taking a medicine, its potential harm, and how it can affect their everyday lives. ${ }^{7}$ Consequently, patient-centered care approaches have been introduced and reportedly improved health communication, promoted patient involvement, and fostered positive relationships with health care providers, thus improving medication adherence. ${ }^{8}$ Health care providers are also beginning to acknowledge that patients can and should confidently make reasonably informed decisions about their own health care. ${ }^{9}$

The growing recognition regarding the importance of patient-centered care has led to the introduction of concordance, defined as agreement between health care providers and patients after negotiation which respects the wishes and beliefs of patients in determining whether, how, and when treatment regimens are to be followed. ${ }^{10}$ It is a process that promotes an open information exchange between health care providers and patients as equals, cultivating a therapeutic alliance, mutual understanding, and cooperation during consultations. ${ }^{11}$ In addition, patients' preferences, views, and personal concerns are also incorporated into health care decisions. ${ }^{12}$

A concordance approach may facilitate the active involvement of patients in decision making about their treatment. Subsequently, patients may have higher levels of self-efficacy in making decisions on their treatment, including medications, as part of their care. ${ }^{13}$ According to Bandura, ${ }^{14}$ self-efficacy is the belief or confidence in one's ability to undertake any specific actions successfully. The authors suggested that self-efficacy is influenced by factors such as verbal persuasion and emotional state. In terms of health care decision making, patients may have higher levels of self-efficacy in decision making if they are provided with good verbal support and are not under negative emotional states such as anxiety or stress..$^{15}$ These go in line with the core value of concordance, which is to promote therapeutic alliance and mutual understanding through open information exchange and dealing with patients' individual emotions and beliefs. ${ }^{16}$
Ever since this concept was conceived, studies have been conducted primarily to measure the acceptance of concordance in health care rather than to measure concordance as a direct outcome. For concordance to be achieved, patients and health care providers must first have positive attitudes toward it. Despite these developments, most studies have focused solely on consultations involving physicians only, with only one study measuring attitudes toward concordance among pharmacists. ${ }^{17}$ However, pharmacists are also an important part of the health care team, are well positioned to communicate with patients about their medications, and can also encourage active involvement of patients in decisions related to medications..$^{18}$ Good patient-centered communication by pharmacists is important and has been shown to improve patient medication adherence and facilitate greater understanding of treatment and higher levels of satisfaction. ${ }^{19}$

In Malaysia, pharmacists are involved in chronic disease management programs to improve medication adherence. For example, most public hospitals have medication therapy adherence clinics (MTACs), in which qualified pharmacists assess and monitor medication adherence in patients with chronic diseases by asking them how they take their medications and matching this to their prescriptions. Patients are also provided with education and counseling support for their diseases and medications during MTAC sessions. Education is provided through booklets that are given to patients based on their disease (eg, diabetes booklet and warfarin information booklet). Despite efforts to improve adherence, studies on the impact of MTAC have shown mixed results, with some studies demonstrating improvement in adherence, ${ }^{20}$ while others indicate that there is still a substantial number of patients who are non-adherent in taking their medications. ${ }^{21,22}$ In addition, no studies on concordance among health care professionals, including pharmacists, have been conducted in Malaysia so far. Therefore, this study aimed to measure both patients' and pharmacists' attitudes toward concordance. Moreover, patients' perceived involvement and confidence in making informed decisions on medications and how these aspects relate to their attitudes toward concordance were also investigated.

\section{Subjects and methods Study design}

A descriptive, cross-sectional study was conducted among patients and pharmacists in three public hospitals in Kuala Lumpur, Malaysia, from June 2017 to September 2017. Ethics approval was obtained from the research ethics 
committee of Universiti Kebangsaan Malaysia (UKM; Ref No: PPI/111/8/JEP-2017-354) and the Medical Research and Ethics Committee, Ministry of Health Malaysia (Ref No: NMRR-17-1471-36916 [IIR]).

Data collection was conducted in MTACs located in the consultation rooms within the outpatient department of the hospitals. Both pharmacists and patients were recruited using convenience sampling. In this study, patients who participated in MTAC services offered by the hospitals, specifically for cardiovascular disease, diabetes mellitus, and hematological diseases, were included. Patients waiting outside the consultation rooms were approached and given an explanation of the study. Patients aged 18 years and older, who could speak or read either Malay or English language, and who had been diagnosed with chronic disease were recruited for this study. Patients who had never participated in any MTAC consultations with pharmacists were excluded. Written informed consent was obtained before participants were presented with a set of questionnaires to be completed, with assistance provided to those who requested.

In addition to patients, pharmacists were also recruited in this study. Qualified and registered pharmacists who were currently providing MTAC consultation services in the study hospitals were recruited and given a set of questionnaires to be completed.

\section{Study instrument}

The patient questionnaire consisted of 34 questions in four sections, including patients' sociodemographic characteristics, attitudes toward concordance, perceived involvement in decision making about medications, and self-efficacy in decision making. Patients were requested to answer the questions based on their prior experience with pharmacist consultations.

The pharmacist questionnaire consisted of 21 questions in two sections, namely pharmacists' sociodemographic characteristics and attitudes toward concordance.

The questionnaires were in both English and the national Malay language. Professional translation service was used to translate the questionnaire to Malay language, before it was back translated by two independent bilinguals to ensure that there were no discrepancies in the translation. Content validation was performed by three hospital pharmacists with experience leading the MTAC services in their respective institutions. A pilot study on 30 patients was conducted prior to the actual data collection, and no difficulties were observed in understanding and answering the questions. No revisions were made after the content validation and pilot study.

\section{Sociodemographic data}

Patients' information on their gender, age, ethnicity, educational qualification, personal monthly income, number of medications currently taken, and number of years in MTAC was recorded.

For pharmacists, their gender, age, educational qualification, and number of years as practicing pharmacists were recorded.

\section{Attitudes toward concordance}

Raynor et al developed the first version of Leeds Attitudes toward Concordance (LATCon) which was then used to measure attitudes toward concordance during clinical consultations among health care professionals, patients, pharmacists, and medical students..$^{9,17,23-25}$ It has been further revised by Flagg in the United States, known as Revised United States Leeds Attitudes toward Concordance (RUSLATCon). ${ }^{24}$ After acquiring approval from the author, the RUS-LATCon was adapted to suit the context of the pharmacy service in Malaysia. The questionnaire consisted of 14 statements rated on a 5-point Likert scale ranging from "strongly disagree" to "strongly agree."

\section{Patients' perceived involvement in decision making about medications}

Patients were asked to rate their level of involvement in decision making about their medication treatment. They were asked to select one of the following options: 1=yes, definitely involved (fully involved); $2=y e s$, but to some extent (partially involved), and $3=$ no (not involved at all). This single question was adapted from the Local Health Services Questionnaire by National Health Service, UK. ${ }^{26}$

\section{Patients' self-efficacy in decision making}

Patients' confidence in making informed decisions about medications was measured using the Decision Self-Efficacy Scale developed by O'Connor. ${ }^{27}$ Permission from the author was sought before it was adapted to suit the context of the study. This questionnaire consisted of 10 statements measured on the scale of $0=$ not at all confident to $4=$ very confident to determine patients' confidence in various situations on the choices of medication taking. Scores on all 10 items were then summed and converted into percentages.

\section{Statistical analyses}

The data were analyzed using SPSS version 22 (IBM Corporation, Armonk, NY, USA). Descriptive statistics were used to characterize samples, including means, frequency, 
and standard deviations. Cronbach's $\alpha$ was performed to determine the internal consistency of the scales used to measure patients' and pharmacists' attitudes toward concordance and patients' self-efficacy in decision making. Independent $t$-test was used to determine significant differences between patients and pharmacists on attitudes toward concordance. One-way analysis of variance (ANOVA) test was used to test significant differences on attitudes toward concordance based on the three groups of patient involvement. Multiple linear regression analyses (forced entry method) were performed to predict sociodemographic factors, attitudes toward concordance, and patients' perceived level of involvement as factors that can affect self-efficacy in decision making. $p<0.05$ is accepted to be statistically significant in this study.

\section{Results}

A total of 389 patients were recruited for this study (Table 1). The mean (SD) age of respondents was 60 years (16.1).

Table I Sociodemographic characteristics of patients

\begin{tabular}{|c|c|c|}
\hline $\begin{array}{l}\text { Descriptive } \\
\text { characteristics }\end{array}$ & $\begin{array}{l}\text { Frequency } \\
(n=389)\end{array}$ & Percentage \\
\hline \multicolumn{3}{|l|}{ Gender } \\
\hline Male & 162 & 41.6 \\
\hline Female & 227 & 58.4 \\
\hline \multicolumn{3}{|l|}{ Age $(\text { years })^{\mathrm{a}}$} \\
\hline Mean \pm SD & $59.58 \pm 16.06$ & \\
\hline Median (IQR) & $62(50-71.75)$ & \\
\hline Range & $18-94$ & \\
\hline \multicolumn{3}{|l|}{ Race } \\
\hline Malay & 257 & 66.1 \\
\hline Chinese & 93 & 23.9 \\
\hline Indian & 33 & 8.5 \\
\hline Others & 6 & 1.5 \\
\hline \multicolumn{3}{|l|}{ Education level } \\
\hline No formal education & 46 & 11.8 \\
\hline Primary school & 86 & 22.1 \\
\hline Secondary school & 177 & 45.5 \\
\hline Diploma/preuniversity & 43 & II.I \\
\hline University (degree, postgraduate) & 37 & 9.5 \\
\hline \multicolumn{3}{|l|}{ Monthly personal income $\mathrm{a}^{\mathrm{a}}$} \\
\hline Not working/retired & 255 & 65.6 \\
\hline$<\mathrm{RM} 2,000$ & 58 & 14.9 \\
\hline $\mathrm{RM} 2,000$ to $\mathrm{RM} 5,000$ & 55 & 14.2 \\
\hline $\mathrm{RM} 5,00 \mathrm{I}$ to $\mathrm{RM} 8,000$ & 14 & 3.6 \\
\hline$>\mathrm{RM} 8,000$ & 6 & 1.6 \\
\hline \multicolumn{3}{|l|}{ Years of follow-up } \\
\hline$<6$ months & 83 & 21.3 \\
\hline $6-12$ months & 42 & 10.8 \\
\hline$>1$ year & 261 & 67.1 \\
\hline \multicolumn{3}{|l|}{ Number of medications taken } \\
\hline $\mathrm{I}-2$ & 128 & 32.9 \\
\hline $3-4$ & 115 & 29.6 \\
\hline$\geq 5$ & 146 & 37.5 \\
\hline
\end{tabular}

Note: a Few missing values.

Abbreviations: IQR, interquartile range; RM, Ringgit Malaysia.
The majority of patients were female $(n=227,58.4 \%)$. In terms of ethnicity, most patients were Malays $(n=257$, $66.1 \%)$, followed by Chinese $(n=93,23.9 \%)$. Most of the patients $(n=257,66.1 \%)$ received at least secondary education and were retired or unemployed $(n=255,65.6 \%)$. More than half of the patients accessed MTAC services with pharmacists for more than a year $(n=261,67.1 \%)$. Approximately onethird $(37.5 \%, n=146)$ of patients were taking five or more types of medications.

There were a total of 93 registered pharmacists included in this study (Table 2). The majority were female $(n=85$, $91.4 \%)$ and aged between 25 and 34 years $(n=75,80.6 \%)$. The ethnic background of most of the pharmacists was Chinese $(n=47,50.5 \%)$, followed by Malay $(n=36,38.7 \%)$. More than half had worked for more than 5 years $(n=68,73.2 \%)$. Most of them spent less than 5 hours/week $(n=75,80.6 \%)$ in clinical consultation with patients.

\section{Attitudes toward concordance among patients and pharmacists}

The internal consistency of the RUS-LATCon completed by pharmacists and patients was demonstrated by a Cronbach's $\alpha$ of 0.77 and 0.84 , respectively. Table 3 presents the mean scores of each scale item for both patients and pharmacists, as well as the independent $t$-test results for differences in attitudes toward concordance between the two samples. Overall, the mean score obtained by patients was $3.84(\mathrm{SD}=0.46)$, while

Table 2 Sociodemographic characteristics of pharmacists

\begin{tabular}{lll}
\hline $\begin{array}{l}\text { Descriptive } \\
\text { characteristics }\end{array}$ & $\begin{array}{l}\text { Frequency } \\
(\mathbf{n}=\mathbf{9 3})\end{array}$ & Percentage \\
\hline $\begin{array}{l}\text { Gender } \\
\text { Male }\end{array}$ & 8 & \\
$\quad$ Female & 85 & 8.6 \\
Age & & 91.4 \\
$25-34$ years & 75 & \\
$35-44$ years & 18 & 80.6 \\
Race & & 19.4 \\
Malay & 36 & \\
Chinese & 47 & 38.7 \\
Indian & 10 & 50.5 \\
Highest academic qualification & & 10.8 \\
Bachelor's degree & 73 & \\
Master's degree & 20 & 78.5 \\
Years of experience as practicing pharmacist & 21.5 \\
$\quad<5$ years & 25 & \\
$5-10$ years & 58 & 26.9 \\
$>10$ years & 10 & 62.4 \\
Hours spent in clinical consultation per week & 10.8 \\
$<5$ hours & 75 & 80.6 \\
$5-10$ hours & 17 & 18.3 \\
$>10$ hours & 1 & 1.1 \\
\hline
\end{tabular}


Table 3 Mean and SD of RUS-LATCon scores and differences between pharmacists and patients

\begin{tabular}{|c|c|c|c|c|}
\hline Statement $^{\mathrm{a}}$ & $\begin{array}{l}\text { Patient score } \\
\text { (mean [SD]), N=389 }\end{array}$ & $\begin{array}{l}\text { Pharmacist score } \\
\text { (mean }[S D]), N=93\end{array}$ & $\begin{array}{l}\text { t-statistic } \\
(d f)\end{array}$ & $p$-value \\
\hline $\begin{array}{l}\text { I. During a counseling session, the pharmacist and patient should treat } \\
\text { each other like equal partners }\end{array}$ & $4.06(0.7 I)$ & $3.91(0.76)$ & $1.753(479)$ & 0.08 \\
\hline $\begin{array}{l}\text { 2. Pharmacists should respect their patients' beliefs and coping abilities } \\
\text { about use of medications }\end{array}$ & $3.99(0.78)$ & $4.18(0.72)$ & $-2.14(479)$ & $0.03 *$ \\
\hline $\begin{array}{l}\text { 3. Pharmacists should pay attention to patients' desires, needs, and } \\
\text { capabilities about use of medications }\end{array}$ & $3.94(0.80)$ & $4.30(0.62)$ & $-4.03(480)$ & $<0.00 I^{*}$ \\
\hline $\begin{array}{l}\text { 4. The patient does not always know how they will follow the } \\
\text { directions provided when taking medication }\end{array}$ & $3.41(1.023)$ & $3.78(0.75)$ & $-4.03^{b}(183.52)$ & $<0.00 I^{*}$ \\
\hline $\begin{array}{l}\text { 5. Pharmacists are hopeful but not always positive that medication } \\
\text { prescribed will improve patients' health }\end{array}$ & $3.69(0.80)$ & $2.78(0.94)$ & $8.572^{b}(125.36)$ & $<0.001^{*}$ \\
\hline $\begin{array}{l}\text { 6. Pharmacists should ask the patient to share their ideas about how } \\
\text { their illness should be treated }\end{array}$ & $3.73(0.94)$ & $3.75(0.72)$ & $-0.29^{b}(\mid 75 . I)$ & 0.81 \\
\hline $\begin{array}{l}\text { 7. Pharmacists should discuss and agree upon a treatment plan with } \\
\text { their patients }\end{array}$ & $3.87(0.85)$ & $4.18(0.66)$ & $-3.32(480)$ & $<0.00 I^{*}$ \\
\hline $\begin{array}{l}\text { 8. Both the patient and pharmacist should agree on a plan to reach the } \\
\text { desired effects of treatment options }\end{array}$ & $3.96(0.76)$ & $4.32(0.59)$ & $-4.32(480)$ & $<0.00 I^{*}$ \\
\hline $\begin{array}{l}\text { 9. Pharmacists should help patients make informed decisions by giving } \\
\text { them information about the risks and benefits of different treatments }\end{array}$ & $4.19(0.75)$ & $4.18(0.59)$ & $-0.9(480)$ & 0.93 \\
\hline $\begin{array}{l}\text { 10. The patient's desired outcomes and willingness to follow directions } \\
\text { are the most critical elements in planning the treatment }\end{array}$ & $3.96(0.75)$ & $4.30(0.72)$ & $-3.95(479)$ & $<0.00 I^{*}$ \\
\hline $\begin{array}{l}\text { 11. During the pharmacist-patient consultation, the patient's decision is } \\
\text { the most important }\end{array}$ & $3.55(1.04)$ & $3.42(0.95)$ & I.I3 (480) & 0.26 \\
\hline $\begin{array}{l}\text { 12. The decision to use medications should be based on what the patient } \\
\text { wants and can achieve }\end{array}$ & 3.30 (1.09) & $3.49(0.94)$ & $-1.74^{b}(156.7)$ & 0.08 \\
\hline $\begin{array}{l}\text { 13. I believe that pharmacists should be more sensitive to how patients } \\
\text { react to the information they give }\end{array}$ & $4.10(0.7 I)$ & $4.16(0.63)$ & $-0.76(479)$ & 0.45 \\
\hline $\begin{array}{l}\text { 14. I believe pharmacists need to learn about patients' beliefs about } \\
\text { medications }\end{array}$ & $3.93(0.83)$ & $4.04(0.72)$ & $-1.199(480)$ & 0.23 \\
\hline Total mean & $3.84(0.46)$ & $3.92(0.37)$ & $-1.54(167.3)$ & 0.13 \\
\hline
\end{tabular}

Notes: a Likert scale: I=strongly disagree, $2=$ disagree, $3=$ neutral, $4=$ agree, $5=$ strongly agree. ${ }^{b}$ Equal variance not assumed. $*$ Significant at $p<0.05$ level.

Abbreviation: RUS-LATCon, Revised United States Leeds Attitudes toward Concordance.

the mean score of pharmacists was $3.92(\mathrm{SD}=0.37)$. The independent $t$-test results showed significant differences between the two samples for seven items. Pharmacists scored significantly higher than patients in six of the items, which pertained to pharmacists' attentiveness (items 2 and 3), uncertainty during consultation (item 4), shared treatment plan agreement (items 7 and 8), and patients' cooperation in planning treatment (item $10 ; p<0.05)$. Patients $(\mathrm{M}=3.69$, $\mathrm{SD}=0.8)$ scored higher than pharmacists $(\mathrm{M}=2.78, \mathrm{SD}=0.94)$ only for item 5 (pharmacists are hopeful but not always positive that medication prescribed will improve patients' health); $t(125.36)=8.572, p<0.01$.

\section{Patients' perceived level of involvement in medication-related decision making}

Among the patients, 168 (43.2\%) reported being fully involved in medication-related decision making, with the remainder reporting partial involvement $(39.6 \%)$ or no involvement at all (16.5\%). The ANOVA showed a significant difference in attitudes toward concordance (as measured by the RUS-LATCon) according to patients' perceived level of involvement in medication-related decision making $(p<0.001$; Table 4). Subsequent post hoc tests revealed significant differences in the mean RUS-LATCon scores between patients who felt fully involved and those who felt partially involved $(p<0.05)$, as well as between those who felt fully involved and those with no involvement at all $(p<0.001)$. The mean score of patients who felt fully involved $(\mathrm{M}=3.94, \mathrm{SD}=0.462)$ was significantly higher than the scores

Table 4 Comparison of RUS-LATCon scores according to patients' perceived level of involvement

\begin{tabular}{|c|c|c|c|c|}
\hline $\begin{array}{l}\text { Perceived level } \\
\text { of involvement }\end{array}$ & $\begin{array}{l}\text { Number } \\
\text { (\%) }\end{array}$ & $\begin{array}{l}\text { Mean } \\
\text { (SD) }\end{array}$ & $\begin{array}{l}\text { F-statistic }{ }^{a} \\
\text { (df) }\end{array}$ & $p$-value \\
\hline Fully involved & $168(43.2)$ & $3.94(0.462)$ & $8.113(2,38 I)$ & $<0.00 I^{b}$ \\
\hline Partially involved & I54 (39.6) & $3.82(0.478)$ & & \\
\hline Not involved at all & $64(16.5)$ & $3.68(0.47 I)$ & & \\
\hline
\end{tabular}

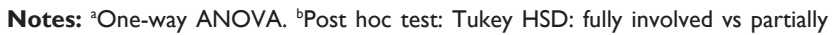
involved, $p=0.048$; fully involved vs not involved at all, $p<0.001$; partially involved vs not involved at all, $p=0.099$.

Abbreviations: ANOVA, analysis of variance; HSD, honest significant difference; RUS-LATCon, Revised United States Leeds Attitudes toward Concordance. 
of patients who felt partially involved ( $\mathrm{M}=3.82, \mathrm{SD}=0.478)$ and those who felt uninvolved $(\mathrm{M}=3.68, \mathrm{SD}=0.471)$. No significant difference was found between patients who felt only partially involved and those not involved at all.

\section{Self-efficacy in decision making}

The Decision Self-Efficacy scale for patients has demonstrated good internal consistency, with a Cronbach's $\alpha$ of 0.84 . Item scores of patients are presented in Table 5 . Generally, the mean percentage of patients' scores was $76.73 \%$ ( $\mathrm{SD}=14.73$ ). Looking at each item, patients scored highest on item 7, "asking for advice from the pharmacists" (mean percentage $=82.51 \%, \mathrm{SD}=20.82$ ), indicating that they have confidence in asking questions about their medications to their pharmacists. The lowest score was for item 9, "handling unwanted pressure from others in making a decision" (mean percentage $=69.62 \%, \mathrm{SD}=25.65$ ).

Multiple linear regression was performed to predict self-efficacy in decision making based on three predictors, namely sociodemographics, attitudes toward concordance, and patients' perceived level of involvement in decision making (Table 6). A significant regression equation for the total model was obtained $(\mathrm{F}[20,355]=6.538, p<0.001)$, with an $R^{2}$ of 0.27 . Four independent variables, namely ethnicity, number of medications taken by the patient, patients' perceived level of involvement, and attitude toward concordance, were found to be significant predictors of selfefficacy in decision making.

In terms of sociodemographics, only ethnicity was found to be a significant predictor, with respondents of Malay ethnicity scoring $5 \%$ higher than did respondents from a Chinese background in self-efficacy in decision making $(p<0.01 ; 95 \%$ CI $1.55,8.3 \%)$. Another significant predictor of self-efficacy in decision making was the number of medications taken by the patient. Patients who took a total of three to four medications scored about $4 \%$ higher than those who took more than five medications ( $p<0.05 ; 95 \%$ CI 0.6 , $7.23 \%$ ). Attitudes toward concordance were found to have a significant linear relationship with self-efficacy in decision making $(p<0.001)$. Increases in patients' agreement with concordance (1-point increment in RUS-LATCon scores) had an $8 \%$ increase in self-efficacy in decision making (95\% CI $4.93,10.94 \%)$. Patients' perceived involvement in their consultation was also a significant predictor of self-efficacy in decision making $(p<0.01)$. Patients who felt that they were fully involved or partially involved in their consultation with pharmacists scored $13.15 \%$ (95\% CI 9.24, 17.06\%) and 7\% (95\% CI 2.99, 11\%) higher, respectively, than did those who felt that they were not involved at all.

\section{Discussion}

Results from this study indicated that the majority of RUS-LATCon item scores were above the scale midpoint for both patients and pharmacists. However, scores for approximately half of the items in the scale showed significant differences between patients and pharmacists, similar to previous studies with other health care professionals and patients. ${ }^{24,25}$ In general, both pharmacists and patients have nearly similar views on certain aspects of concordance. For example, both parties generally agreed that patients and pharmacists should be treated as equals in a consultation and that patients' beliefs and coping abilities regarding medication use should be respected. This finding may indicate that Malaysian patients and pharmacists generally accept the importance of patient-centered care and are increasingly aware of an equal partnership in consultation. This contrasts with the finding of a study in China, whereby the patients in that study tended to recognize and accept an unequal partnership during health communication. ${ }^{28}$ It has been suggested that such perceptions can be influenced by a long tradition of

Table 5 Decision Self-Efficacy Scale score (patients' confidence in making informed decision)

\begin{tabular}{|c|c|c|}
\hline Confidence in & Mean (SD) & Score (\%) (SD) \\
\hline I. Getting the facts about medication choices available & $2.96(0.920)$ & $73.9(22.97)$ \\
\hline 2. Getting the facts about benefits of medications & $3.10(0.773)$ & $77.46(19.33)$ \\
\hline 3. Getting the facts about side effects of medications & $3.02(0.983)$ & $75.52(24.57)$ \\
\hline 4. Understanding the information enough to make a decision to take medications & $3.23(0.858)$ & $78.04(21.44)$ \\
\hline 5. Asking questions about medications without feeling foolish & $3.14(0.939)$ & $78.43(23.48)$ \\
\hline 6. Expressing concern about the medications & $3.10(0.969)$ & $77.53(22.69)$ \\
\hline 7. Asking for advice from the pharmacists & $3.30(0.833)$ & $82.51(20.82)$ \\
\hline 8. Figuring out the decision about medication that best suits the patient & $3.08(0.948)$ & $76.94(23.69)$ \\
\hline 9. Handling unwanted pressure from others in making a decision & $2.78(1.026)$ & $69.62(25.65)$ \\
\hline 10. Letting the pharmacists know what is the best for the patient & $3.10(0.993)$ & $77.40(24.82)$ \\
\hline Total & $3.07(0.589)$ & $76.73(14.73)$ \\
\hline
\end{tabular}

Note: aScored from $0=$ not confident at all to $4=$ very confident, then converted to percentage scores by multiplying each item by 25 . 
Table 6 Multiple regression analysis in predicting self-efficacy in decision making

\begin{tabular}{|c|c|c|c|c|}
\hline Predictors $^{a}$ & Final beta & SE beta & $95 \% \mathrm{Cl}$ & $\begin{array}{l}\text { Standardized } \\
\text { beta }\end{array}$ \\
\hline Constant (final) & 37.25 & 7.579 & 22.345 to 52.155 & \\
\hline \multicolumn{5}{|l|}{ Sociodemographics } \\
\hline Age & -0.006 & 0.053 & -0.110 to 0.099 & -0.006 \\
\hline \multicolumn{5}{|c|}{ Gender (male as reference) } \\
\hline Female & -1.001 & 1.440 & -1.832 to 3.834 & -0.034 \\
\hline \multicolumn{5}{|l|}{ Race (Malay as reference) } \\
\hline Chinese & -4.926 & 1.717 & -8.302 to -1.549 & $-0.143 * *$ \\
\hline Indian & -3.987 & 2.528 & -8.959 to 0.985 & -0.075 \\
\hline Others & -2.392 & 5.993 & -14.177 to 9.394 & -0.019 \\
\hline \multicolumn{5}{|c|}{ Monthly household income (no income as reference) } \\
\hline$<\mathrm{RM} 2,000$ & -0.04 & 2.016 & -4.006 to 3.925 & -0.001 \\
\hline RM2,000 to RM5,000 & -2.921 & 2.242 & -7.330 to 1.488 & -0.069 \\
\hline RM5,00I to RM8,000 & -0.760 & 3.953 & -8.534 to 7.014 & -0.010 \\
\hline$>\mathrm{RM} 8,000$ & -0.746 & 5.751 & -12.056 to 10.563 & -0.006 \\
\hline \multicolumn{5}{|c|}{ Education level (secondary school as reference) } \\
\hline No formal education & -2.833 & 2.395 & -7.544 to 1.877 & -0.063 \\
\hline Primary school & 0.278 & 1.865 & -3.390 to 3.946 & 0.008 \\
\hline Diploma & 0.791 & 2.359 & -3.849 to 5.430 & 0.017 \\
\hline Degree/postgraduate & 3.238 & 2.715 & -2.100 to 8.577 & 0.066 \\
\hline \multicolumn{5}{|c|}{ Number of medications taken ( $>5$ medications as reference) } \\
\hline I-2 medicines & 1.787 & 1.649 & -1.457 to $5.03 \mid$ & 0.057 \\
\hline 3-4 medicines & 3.917 & 1.685 & 0.603 to 7.231 & $0.122 *$ \\
\hline \multicolumn{5}{|c|}{ Years of follow-up with pharmacists ( $<6$ months as reference) } \\
\hline $6-12$ months & -2.308 & 2.566 & -7.354 to 2.738 & -0.049 \\
\hline$>1$ year & -0.236 & 1.752 & -3.682 to 3.210 & -0.008 \\
\hline \multicolumn{5}{|c|}{ Attitudes toward concordance } \\
\hline RUS-LATCon score & 7.934 & 1.530 & 4.926 to 10.942 & $0.248 * * *$ \\
\hline \multicolumn{5}{|c|}{ Patients' perceived level of involvement (not involved at all as reference) } \\
\hline Definitely involved & 13.146 & 2.036 & 2.989 to 10.998 & $0.233^{* *}$ \\
\hline Partially involved & 6.994 & 1.989 & 9.235 to 17.058 & $0.445 * * *$ \\
\hline
\end{tabular}

Notes: aMultiple linear regression (forced entry), $R^{2}$ of $0.27, F(20,355)=6.538, p<0.001$. ${ }^{*} p<0.05$. $* * p<0.01$. $*_{* *}^{*} p<0.001$.

Abbreviations: RM, Ringgit Malaysia; RUS-LATCon, Revised United States Leeds Attitudes toward Concordance; SE, standard error.

health care professionals' paternalistic attitudes and patients' habitual acceptance of dominant health care professional roles in consultation. ${ }^{28}$

However, on the subscale level, pharmacists demonstrated stronger agreement than patients about the importance of concordance in planning shared treatment goals and paying attention to individual patients' abilities in medication use. Previous findings suggested that patients are less aware of the role that pharmacists can play in aiding them with their health care plan and management. Patients tend to relate these roles with other health care professionals (eg, physicians) instead. ${ }^{29}$ Therefore, efforts should be made to increase patients' awareness of the role of pharmacists in supporting patients' decision making, particularly regarding medication treatment. Pharmacists can contribute by encouraging patients to speak out and discuss their views on their goals and expectations.
Pharmacists tended to disagree with the statement that they are hopeful, but not always positive that the prescribed medications can help improve patients' health. In contrast, patients felt that pharmacists may not always show positivity regarding the benefits of patients' medications. One possible explanation is that pharmacists might not have imparted sufficient assurance to the patients about their medication during the consultation. Since this study included chronically ill patients, the majority of whom were involved in longterm pharmacological therapy (eg, lifelong anticoagulant therapy, diabetes treatment, and chronic myeloid leukemia treatment), it is possible that a certain level of medication uncertainty may arise after taking the medications for some time. Moreover, contributing factors such as an absence of symptoms and fear of adverse effects could raise uncertainty about the benefits of the medication, which could ultimately impact adherence. ${ }^{30}$ Consequently, pharmacists should 
consistently provide reassurance and reassess patients' understanding of their current conditions to tackle any uncertainty issues in the consultation.

Pharmacists expect that patients do not always follow the instructions for taking medication. However, patients' scores showed otherwise, implying that there is a gap in expectations of medication-taking behavior between pharmacists and patients, which needs to be addressed. Previous results showed that health care providers held the assumption that patients do not value the importance of taking medications, which might explain why pharmacists feel that patients show low medication adherence. ${ }^{24}$ This finding emphasizes the importance of improving the implementation of a patientcentered approach by pharmacists. A patient-centered approach that supports open information exchange, such as utilizing feedback from patients, can encourage further discussion of current regimens and help pharmacists and patients build stronger rapport. ${ }^{31}$ In addition, patients who are found to be non-adherent should be provided with more tailored information and support (eg, identifying individual issues that cause patients to be non-adherent), rather than just repeating the typical education process. ${ }^{32}$

Compared with scores on other items, both pharmacists and patients scored relatively low in items measuring the extent of patients' decisional role in medication taking. This finding signifies that both parties felt that pharmacists should take a larger role in the final decision on taking medication, which corroborates with previous findings that a large proportion of patients still prefer their health care provider to make medication-related decisions, despite wanting to be actively involved and able to share their beliefs and opinions on treatments. ${ }^{33,34}$

In this study, patients who felt that they were fully involved in decision making about their medications had significantly more favorable attitudes toward concordance than did those who felt only partially involved or uninvolved (Table 4). This is not surprising, as the concept of concordance puts patients at the center of the consultation, which promotes active information sharing, establishes a therapeutic alliance, and addresses individual beliefs, feelings, and agreement about various treatment options. ${ }^{16}$ Thus, patients with a positive attitude toward concordance could have a higher preference for active involvement in medication-related decision making with pharmacists. Conversely, it is possible that patients who felt that they were given the chance to be actively involved in medication-related decision making appreciate the benefits of involvement, thus leading to a more positive attitude toward concordance. Being an actively involved patient has its benefits, as previous studies found that patients who played an active role tend to have greater personal control and better health outcomes compared with those who are passive. ${ }^{35,36}$

Moreover, the multiple linear regression analyses also showed that both patients' attitudes toward concordance and their involvement are associated with patients' self-efficacy in decision making. Patients with positive attitudes toward concordance who felt actively involved were more confident in making decisions regarding taking medication compared with those who felt partially involved or uninvolved. Previous studies suggested that patients with better health literacy tended to be more actively involved and have higher levels of self-efficacy. ${ }^{37}$ It is important for patients to have sufficient information about their medications, as it is also possible that patients can unknowingly make a wrong decision despite being confident about it. Use of simple visual displays of information or analogies and decision support tools can also improve patient understanding before making an informed decision. ${ }^{38,39}$

In this regard, pharmacists can play an important role in encouraging patient involvement, raising awareness on concordance, and improving patient health literacy to improve patients' confidence in decision making. They can collaborate with other health care professionals to identify patients who need individualized guidance on decision making. ${ }^{40}$ Counseling support for various information about treatment regimens and diseases has also been shown to improve patient involvement and knowledge about their own illness. ${ }^{41}$ Pharmacists may also benefit from additional training on patient-centered communication skills, and utilizing decision support tools and question prompts in their consultations, to encourage active involvement of patients and forge better patient-provider relationships. ${ }^{13}$

Ethnicity and the number of medications taken were also found to be predictors of patients' self-efficacy in decision making. Malaysia is a multiethnic country with people from diverse cultural backgrounds. Patients from a Malay ethnic background were shown to have higher levels of self-efficacy than those from a Chinese background. As most consultations are conducted with English and Malay as the medium of communication, language barriers between pharmacists and patients may explain the difference in self-efficacy scores. This finding is supported by another study, whereby Malay patients were shown to have a higher preference for involvement in decision making. ${ }^{42}$ In addition, a lower and more manageable number of medications can improve patients' confidence in decision making. If we associate a lower number of medications with fewer comorbid conditions, 
then an inference can be drawn in that patients with more comorbid conditions may find making a medication-related decision about their illnesses more challenging. In addition, studies have demonstrated that patients with a higher number of comorbidities have a lower adherence rate and poorer outcomes from their medications. ${ }^{43}$

Interestingly, age does not seem to be a significant predictor in this study, contradicting findings that younger patients are more confident and want to be actively involved in medication-related decision making. ${ }^{44}$ There is one possible explanation for this finding: many of the patients in the current study were elderly and had family members accompanying them during consultation. Therefore, family involvement might play a significant role in the patients' decision-making process. Lee and $\mathrm{Ng}^{9} \mathrm{~s}^{45}$ findings support this claim; strong family involvement played a major role for Malaysian patients in making decisions. Future study should focus on the role of caregivers in the medication-related decision-making process during consultation.

\section{Limitations}

Although this study has provided useful insights into decision making in pharmacist-patient consultations, several limitations must be acknowledged. Data collection was limited to only three centers, which may limit the generalizability of the study's findings. Furthermore, not all types of MTAC services were represented in our study. Therefore, results may not be generalized to the entire population of MTAC patients.

In addition, as this study has a cross-sectional design, causal inferences cannot be drawn based on the analyses. Moreover, patients were asked to base their answers on past consultations with pharmacists, which may introduce some recall bias. However, this bias was minimized as most patients had short follow-up intervals after their last consultation. Patients may not always follow-up with the same pharmacist in every appointment; thus, there may be some undue variations between each pharmacist which may indirectly affect the study results. There is also the possibility of a social desirability bias as patients and pharmacists might report more favorable responses.

\section{Conclusion}

In general, patients who felt more involved in their consultations had better attitudes toward concordance and greater confidence in making a medication-related decision. In addition, ethnicity and the number of medications taken are also significant predictors of self-efficacy in decision making. Further study is recommended on interventions to equip pharmacists with ways to support and encourage patient involvement in medication-related decision making.

\section{Acknowledgments}

We would like to express our sincerest gratitude to Mrs Tassha Hilda, statistician of Clinical Research Centre, for her statistical consultation, and all the pharmacists and staff nurses of UKM Medical Centre, Hospital Kuala Lumpur, and Hospital Sungai Buloh. We would also like to thank UKM for the research funding (code: GGPM-2014-058). We acknowledge the Director General of the Ministry of Health, Malaysia, for permission to publish this article.

\section{Disclosure}

The authors report no conflicts of interest in this work.

\section{References}

1. Royal Pharmaceutical Society. Medicines Optimisation: Helping patients to make the most of medicines. [May 2013]. Available from: https://www.rpharms.com/Portals/0/RPS\%20document\%20library/ Open $\% 20$ access/Policy/helping-patients-make-the-most-of-theirmedicines.pdf. Accessed December 1, 2016.

2. De Geest S, Sabaté E. Adherence to long-term therapies: evidence for action. Eur J Cardiovasc Nurs. 2003;2(4):323.

3. Haynes RB, Yao X, Degani A, Kripalani S, Garg AX, McDonald HP. Interventions to enhance medication adherence. Cochrane Database Syst Rev. 2005;4:CD000011.

4. NCPIE NC on PI and E [webpage on the Internet]. America's Other Drug Problem Poor Medication Adherence. 2007. Available from: http://www.marketwired.com/press-release/americas-other-drug-problem-poor-medication-adherence-756583.htm. Accessed December 20, 2016.

5. Wilson SR, Strub P, Buist AS, et al; Better Outcomes of Asthma Treatment (BOAT) Study Group. Shared treatment decision making improves adherence and outcomes in poorly controlled asthma. Am J Respir Crit Care Med. 2010;181(6):566-577.

6. Osterberg L, Blaschke T. Adherence to medication. NEngl J Med. 2005; 353(5):487-497.

7. Horne R, Weinman J, Barber N, Elliott R. Concordance, adherence and compliance in medicine taking. Rep Natl Co-ord Cent NHS Serv Deliv Organ R D. 2005:1-331.

8. Stewart M. Towards a global definition of patient centred care. The patient should be the judge of patient centred care. BMJ. 2001; 322(7284):444-445.

9. Knapp P, Raynor DK, Thistlethwaite JE, Jones MB. A questionnaire to measure health practitioners' attitudes to partnership in medicine taking: LATCon II. Health Expect. 2009;12(2):175-186.

10. Marinker M, Blekinsopp A, Bond C. From Compliance to Concordance: Achieving Shared Goals in Medicine Taking. London: Royal Pharmaceutical Society of Great Britain; 1997.

11. Snowden A, Martin C, Mathers B, Donnell A. Concordance: a concept analysis. $J$ Adv Nurs. 2013;70(1):46-59.

12. Jordan JL, Ellis SJ, Chambers R. Defining shared decision making and concordance: are they one and the same? Postgrad Med J. 2002; 78(921):383-384.

13. Coulter A, Parsons S, Askham J. Where Are the Patients in Decision-Making About Their Own Care? Heal Syst Heal Wealth; 2008:1-26. Available from: http://www.who.int/management/general/ decisionmaking/WhereArePatientsinDecisionMaking.pdf. Accessed September 1, 2018. 
14. Bandura A. Self-Efficacy: The Exercise of Control. New York: Freeman; 1997.

15. Hoffman AJ. Enhancing self-efficacy for optimized patient outcomes through the theory of symptom self-management. Cancer Nurs. 2013; 36(1):E16-E26.

16. Bell JS, Airaksinen MS, Lysles A, Chen TF, Aslani P. Concordance is not synonymous with compliance or adherence. Br J Clin Pharmacol. 2007:29(1 suppl 64):2005-2008.

17. Kansanaho HM, Puumalainen II, Varunki MM, Airaksinen MSA, Aslani P. Attitudes of Finnish community pharmacists toward concordance. Ann Pharmacother. 2004:38(11):1946-1953.

18. Blagburn J, Simpson S. Pharmacy Professionals Use Shared Decision Making Approaches to Help Patients Better Understand Their Medicines. Newcastle, UK: The Health Foundation; 2014.

19. Stevenson FA, Cox K, Britten N, Dundar Y. A systematic review of the research on communication between patients and health care professionals about medicines: the consequences for concordance. Health Expect. 2004;7(3):235-245.

20. Bakar ZA, Fahrni ML, Khan TM. Patient satisfaction and medication adherence assessment amongst patients at the diabetes medication therapy adherence clinic. Diabetes Metab Syndr. 2016;10(2 suppl 1):S139-S143.

21. Lim PC, Lim K. Evaluation of a pharmacist-managed diabetes medication therapy adherence clinic. Pharm Pract (Granada). 2010;8(4): 250-254.

22. Butt M, Mhd Ali A, Bakry MM, Mustafa N. Impact of a pharmacist led diabetes mellitus intervention on $\mathrm{HbAlc}$, medication adherence and quality of life: a randomised controlled study. Saudi Pharm J. 2016; 24(1):40-48.

23. Raynor DK, Thistlethwaite J, Hart K, Knapp P. Are health professionals ready for the new philosophy of concordance in medicine taking? Int $J$ Pharm Pract. 2001;9(2):81-84.

24. Flagg AJ. Patient/provider concordance: Instrument development. Proquest. 2010.

25. De las Cuevas C, Rivero-Santana A, Perestelo-Pérez L, Pérez-Ramos J, Serrano-Aguilar P. Attitudes towards concordance in psychiatry: a comparative, cross-sectional study of psychiatric patients and mental health professionals. BMC Psychiatry. 2012;12(1):53.

26. NHS. Local Health Services Questionnaire. Natl Surv Program PCT Core Quest 2005. 2004.

27. O'Connor AM. User Manual Decision Self-Efficacy Scale My Confidence in Making an Informed Choice. Ottawa: 2002. Available from: https://decisionaid.ohri.ca/docs/develop/User_Manuals/UM_ Decision_SelfEfficacy.pdf. January 1, 2017.

28. He W, Bonner A, Anderson D. Translation and psychometric properties of the Chinese version of the Leeds attitudes to concordance II scale. BMC Med Inform Decis Mak. 2015;15:60.

29. Worley MM, Schommer JC, Brown LM, et al. Pharmacists' and patients' roles in the pharmacist-patient relationship: are pharmacists and patients reading from the same relationship script? Res Social Adm Pharm. 2007;3(1):47-69.
30. Vermiere E, Hearnshaw H, Van Royen P, Deneken J. Patient adherence to treatment: three decades of research: a comprehensive review. J Clin Pharm Ther. 2001;26(5):331-342.

31. Kuntz JL, Safford MM, Singh JA, et al. Patient-centered interventions to improve medication management and adherence: a qualitative review of research findings. Patient Educ Couns. 2014;97(3):310-326.

32. National Institute for health and Clinical Excellence [webpage on the Internet]. Medicines Adherence: Involving Patients in Decisions about Prescribed Medicines and Supporting Adherence. Clin Guide 76; 2009. Available from: https://www.nice.org.uk/guidance/cg76. Accessed November 1, 2017.

33. Levinson W, Kao A, Kuby A, Thisted RA. Not all patients want to participate in decision making. A national study of public preferences. J Gen Intern Med. 2005;20(6):531-535.

34. Mah HC, Muthupalaniappen L, Chong WW. Perceived involvement and preferences in shared decision-making among patients with hypertension. Fam Pract. 2016;33(3):296-301.

35. Brody DS, Miller SM, Lerman CE, Smith DG, Caputo GC. Patient perception of involvement in medical care: relationship to illness attitudes and outcomes. J Gen Intern Med. 1989;4(6):506-511.

36. Vahdat S, Hamzehgardeshi L, Hessam S, Hamzehgardeshi Z. Patient involvement in health care decision making: a review. Iran Red Crescent Med J. 2014;16(1):1-7.

37. Ng C-J, Lee P-Y, Lee Y-K, et al. An overview of patient involvement in healthcare decision-making: a situational analysis of the Malaysian context. BMC Health Serv Res. 2013;13(1):408.

38. Robinson JH, Callister LC, Berry JA, Dearing KA. Patient-centered care and adherence: definitions and applications to improve outcomes. J Am Acad Nurse Pract. 2008;20(12):600-607.

39. The Health Foundation [webpage on the Internet]. Implementing Shared Decision Making. 2013. Available from: www.health.org.uk/ publications/the-magic-programme-evaluation. Accessed November 1, 2017.

40. Légaré F, Stacey D, Pouliot S, et al. Interprofessionalism and shared decision-making in primary care: a stepwise approach towards a new model. J Interprof Care. 2011;25(1):18-25.

41. Younas M, Bradley E, Holmes N, Sud D, Maidment ID. Mental health pharmacists views on shared decision-making for antipsychotics in serious mental illness. Int J Clin Pharm. 2016;38(5):1191-1199.

42. Nies YH, Islahudin F, Chong WW, et al. Treatment decision-making among breast cancer patients in Malaysia. Patient Prefer Adherence. 2017;11:1767-1777.

43. Sufiza Ahmad N, Ramli A, Islahudin F, Paraidathathu T. Medication adherence in patients with type 2 diabetes mellitus treated at primary health clinics in Malaysia. Patient Prefer Adherence. 2013;7: 525-530.

44. Coulter A, Collins A. Making Shared Decision-Making a Reality: No Decision about Me, Without Me. London, UK: The King's Fund; 2011.

45. Lee YK, Ng CJ. The state of shared decision making in Malaysia. Z Evid Fortbild Qual Gesundhwes. 2017;123-124:66-68.
Patient Preference and Adherence

\section{Publish your work in this journal}

Patient Preference and Adherence is an international, peer-reviewed, open access journal that focuses on the growing importance of patient preference and adherence throughout the therapeutic continuum. Patient satisfaction, acceptability, quality of life, compliance, persistence and their role in developing new therapeutic modalities and compounds to optimize

\section{Dovepress}

clinical outcomes for existing disease states are major areas of interest for the journal. This journal has been accepted for indexing on PubMed Central. The manuscript management system is completely online and includes a very quick and fair peer-review system, which is all easy to use. Visit http://www. dovepress.com/testimonials.php to read real quotes from published authors. 